\title{
Studies of densities, viscosities and ultrasonic speeds of binary mixtures containing isopropyl alcohol and ketones at different temperatures
}

\author{
S. S. J. Srinivas ${ }^{1}$, B. Tulasi Koteswari Bai ${ }^{2}$, K. Babu Rao ${ }^{1}$, \\ K. Narendra ${ }^{3}$, M. Sarath Babu ${ }^{1, *}$ \\ ${ }^{1}$ Department of Chemistry, MIC College of Technology, Kanchikacharla - 521180, India \\ ${ }^{2}$ Department of Chemistry, Sir C. R. Reddy College for Women, Eluru - 500026, India \\ ${ }^{3}$ Department of Physics, V. R. Siddahrtha Engineering College, Vijayawada - 520007, India \\ *E-mail address: mogalapusarath@rediffmail.com
}

\begin{abstract}
The densities, viscosities and ultrasonic velocities of binary liquid mixtures of Isopropyl alcohol with acetophenone and methyl isobutyl ketone (MIBK) have been measured at temperatures 298.15 and $308.15 \mathrm{~K}$ over the entire range of mole fraction. From these data, acoustical parameters such as adiabatic compressibility $(\beta)$, free volume $\left(\mathrm{V}_{\mathrm{f}}\right)$ and free length $\left(\mathrm{L}_{\mathrm{f}}\right)$ have been estimated using the standard relations. The results are interpreted in terms of molecular interactions present in the mixtures.
\end{abstract}

Keywords: Ultrasonic velocity; density; viscosity; acoustic parameters

\section{INTRODUCTION}

Liquid mixtures, rather than single component liquid system, are used in product formulations and processing in many industrial applications. Binary mixtures are of considerable importance in industries such as Pharmaceutical, petrochemical and dyes. Various methods are avialable to identify the type and strength of the intermolecular interactions and ultrasonic study is one of such reliable and more commonly used study.

To study the departure of a real liquid mixture behaviour from ideality, thermodynamic and transport properties of liquid mixtures have been extensively used [1,2]. To study the intermolecular interactions between the various species present in the mixture, these properties have been widely used $[3,4]$. MIBK is a mildely associating liquid.

Intermolecular free length is an important physical property of liquid mixtures which mainly affects the sound velocity. The intermolecular free length decreases with decrease of temperature and hence the close packing of molecules which in effect decreases the sound velocity $[5,6]$. The compressibility decreases with increase of velocity that gives insight into the structure making and structure breaking of components in binary mixtures [7,18-20]. 
In this work we report the experimental values of the density, viscosity and ultrasonic velocity of the above binary mixtures at the temperatures 298.15 and $308.15 \mathrm{~K}$. These data have been used to calculate various acoustical parameters like adiabatic compressibility $(\beta)$, free volume $\left(\mathrm{V}_{\mathrm{f}}\right)$ and free length $\left(\mathrm{L}_{\mathrm{f}}\right)$.

\section{EXPERIMENTAL}

\section{1. Materials}

The mass fraction purity of the liquids (obtained from Merck) was as follows: isopropyl alcohol (0.990), acetophenone (0.990) and MIBK (0.980). All the liquids used were further purified by standard procedure [8].

\section{2 Procedure}

The densities of pure liquids and liquid mixtures were measured by using a specific gravity bottle with an accuracy of $\pm 0.5 \%$. Weights were measured with an electronic balance capable of measuring up to $0.0005 \mathrm{gm}$. An average of 4-5 measurements was taken for each sample.

Using Ostwald's viscometer, viscosities were measured at the desired temperature. It was calibrated using water and benzene. The flow time has been measured after the attainment of bath temperature by each mixture. The flow measurements were made with an electronic stopwatch with a precision of $0.01 \mathrm{~s}$. The viscosities $\eta$, were obtained from the following relation:

$$
\eta=\mathrm{k} \cdot \rho \cdot \mathrm{t}
$$

where $\mathrm{k}, \rho$ and $\mathrm{t}$, are viscometric constant, density of liquid and time of efflux for a constant volume of liquid respectively. For all pure compounds and mixtures, 3-5 measurements were performed and the average of these values was used in all calculations. The values are accurate to $\pm 0.002 \mathrm{cP}$.

By using single crystal ultrasonic pulse echo interferometer (Mittal enterprises, India; Model: F-80X) the ultrasonic velocities were measured. It consists of a high frequency generator and a measuring cell. The measurements of ultrasonic velocities were made at a fixed frequency of $3 \mathrm{MHz}$. The calibration of the equipment was done by measuring the velocity in carbon tetrachloride and benzene. The ultrasonic velocity has an accuracy of \pm 1 $\mathrm{m} / \mathrm{s}$. By circulating water around the liquid cell from thermostatically controlled constant temperature water bath the temperature was controlled.

\section{RESULTS AND DISCUSSION}

The experimental values of density, viscosity and ultrasonic velocity in case of all the mixtures over the entire range of composition and at temperatures, $\mathrm{T}=298.15$ and $308.15 \mathrm{~K}$ are given in Table 1. These values are used to calculate various parameters like adiabatic compressibility $(\beta)$, free volume $\left(\mathrm{V}_{\mathrm{f}}\right)$ and free length $\left(\mathrm{L}_{\mathrm{f}}\right)$ by using the following standard relations:

Adiabatic compressibility, 


$$
\beta=1 / \rho u^{2}
$$

where $\rho$ is the density of the mixture and $u$ is the ultrasonic velocity.

Free volume,

$$
\mathrm{V}_{\mathrm{f}}=\left(\mathrm{M}_{\mathrm{eff}} \mathrm{u} / \mathrm{K \eta}\right)^{3 / 2}
$$

where $\mathrm{M}_{\mathrm{eff}}$ is the effective molecular weight and $\mathrm{K}$ is proportionality constant, which is sensitive to molecular phenomenon.

Inter molecular free length,

$$
\mathrm{L}_{\mathrm{f}}=\mathrm{K}_{\mathrm{T}} \cdot \beta^{1 / 2}
$$

where $\mathrm{K}_{\mathrm{T}}$ is the temperature dependent constant [9].

\begin{tabular}{|c|c|c|c|c|c|c|}
\hline $\mathbf{X}_{1}$ & $\rho\left(\mathrm{Kg} / \mathrm{m}^{3}\right)$ & $\begin{array}{c}\eta \times 10^{-3} \\
\left(\mathrm{Nsm}^{-2}\right)\end{array}$ & $\mathbf{u}(\mathbf{m} / \mathbf{s})$ & $\rho\left(\mathrm{Kg} / \mathrm{m}^{3}\right)$ & $\begin{array}{c}\eta \mathrm{x10}^{-3} \\
\left(\mathrm{Nsm}^{-2}\right)\end{array}$ & $\mathbf{u}(\mathbf{m} / \mathbf{s})$ \\
\hline & \multicolumn{6}{|c|}{ Isopropyl alcohol + acetophenone } \\
\hline & \multicolumn{3}{|c|}{$298.15 \mathrm{~K}$} & \multicolumn{3}{|c|}{$308.15 \mathrm{~K}$} \\
\hline 0.0000 & 1028.00 & 1.7347 & 1512.63 & 1012.40 & 1.4257 & 1456.32 \\
\hline 0.1443 & 998.24 & 1.7528 & 1463.47 & 994.99 & 1.4320 & 1424.37 \\
\hline 0.2751 & 975.69 & 1.7743 & 1418.42 & 972.09 & 1.4404 & 1392.63 \\
\hline 0.3941 & 948.57 & 1.7877 & 1383.42 & 945.13 & 1.4613 & 1361.05 \\
\hline 0.5030 & 926.32 & 1.8158 & 1348.42 & 922.23 & 1.4677 & 1332.63 \\
\hline 0.6028 & 900.80 & 1.8380 & 1310.53 & 897.60 & 1.4739 & 1294.74 \\
\hline 0.6948 & 877.05 & 1.8687 & 1274.63 & 873.88 & 1.4974 & 1263.47 \\
\hline 0.7798 & 853.18 & 1.8815 & 1243.21 & 850.07 & 1.5063 & 1231.05 \\
\hline 0.8586 & 830.23 & 1.9007 & 1213.79 & 826.46 & 1.5152 & 1200.16 \\
\hline 0.9318 & 808.69 & 1.9376 & 1180.73 & 800.00 & 1.5351 & 1154.79 \\
\hline \multirow[t]{3}{*}{1.0000} & 780.50 & 1.9600 & 1152.63 & 773.60 & 1.5504 & 1127.37 \\
\hline & \multicolumn{6}{|c|}{ Isopropyl alcohol + MIBK } \\
\hline & \multicolumn{3}{|c|}{$298.15 \mathrm{~K}$} & \multicolumn{3}{|c|}{$308.15 \mathrm{~K}$} \\
\hline 0.0000 & 795.70 & 0.6139 & 1196.84 & 785.92 & 0.4941 & 1171.58 \\
\hline 0.1538 & 791.10 & 0.7127 & 1190.37 & 784.40 & 0.5876 & 1166.26 \\
\hline 0.2902 & 789.20 & 0.8084 & 1185.31 & 783.20 & 0.6747 & 1162.10 \\
\hline 0.4121 & 788.70 & 0.8587 & 1181.05 & 782.10 & 0.8021 & 1158.95 \\
\hline 0.5216 & 787.90 & 0.9515 & 1176.26 & 781.80 & 0.8646 & 1152.63 \\
\hline 0.6205 & 784.50 & 1.0279 & 1170.57 & 779.70 & 0.9585 & 1146.32 \\
\hline 0.7104 & 783.40 & 1.1876 & 1167.26 & 778.60 & 1.0473 & 1143.16 \\
\hline 0.7924 & 782.70 & 1.3314 & 1164.10 & 777.20 & 1.1414 & 1140.00 \\
\hline 0.8674 & 781.90 & 1.5926 & 1158.95 & 775.90 & 1.2545 & 1134.68 \\
\hline 0.9364 & 781.00 & 1.7300 & 1155.78 & 774.60 & 1.3680 & 1131.53 \\
\hline 1.0000 & 780.50 & 1.9600 & 1152.63 & 773.60 & 1.5504 & 1127.37 \\
\hline
\end{tabular}

Table 1. Density $(\rho)$, viscosity $(\eta)$ and ultrasonic velocity $(u)$ values of the binary liquid mixtures at different temperatures.

Figure 1 to $3(\mathrm{a}, \mathrm{b})$ shows the variation of $\beta, \mathrm{V}_{\mathrm{f}}$ and $\mathrm{L}_{\mathrm{f}}$ respectively with molefraction of isopropyl alcohol. From Table 1 it is observed that as the molefraction of isopropyl alcohol 
increases the density and ultrasonic velocity values decreases whereas viscosity values increases at all temperatures and for the two systems choosen.

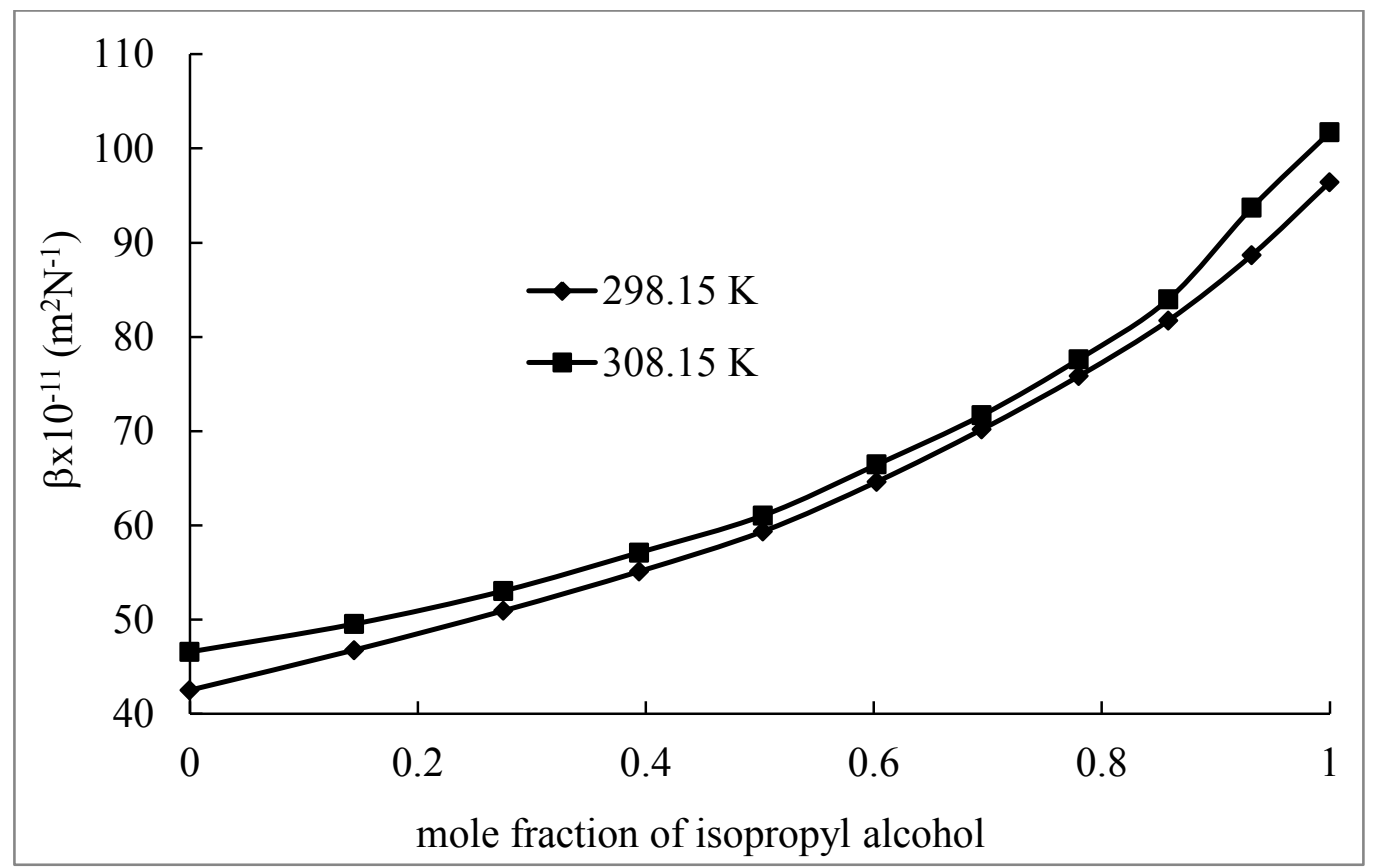

Fig. 1(a). Variation of adiabatic compressibility with mole fraction of isopropyl alcohol for isopropyl alcohol + acetophenone mixture at different temperatures.

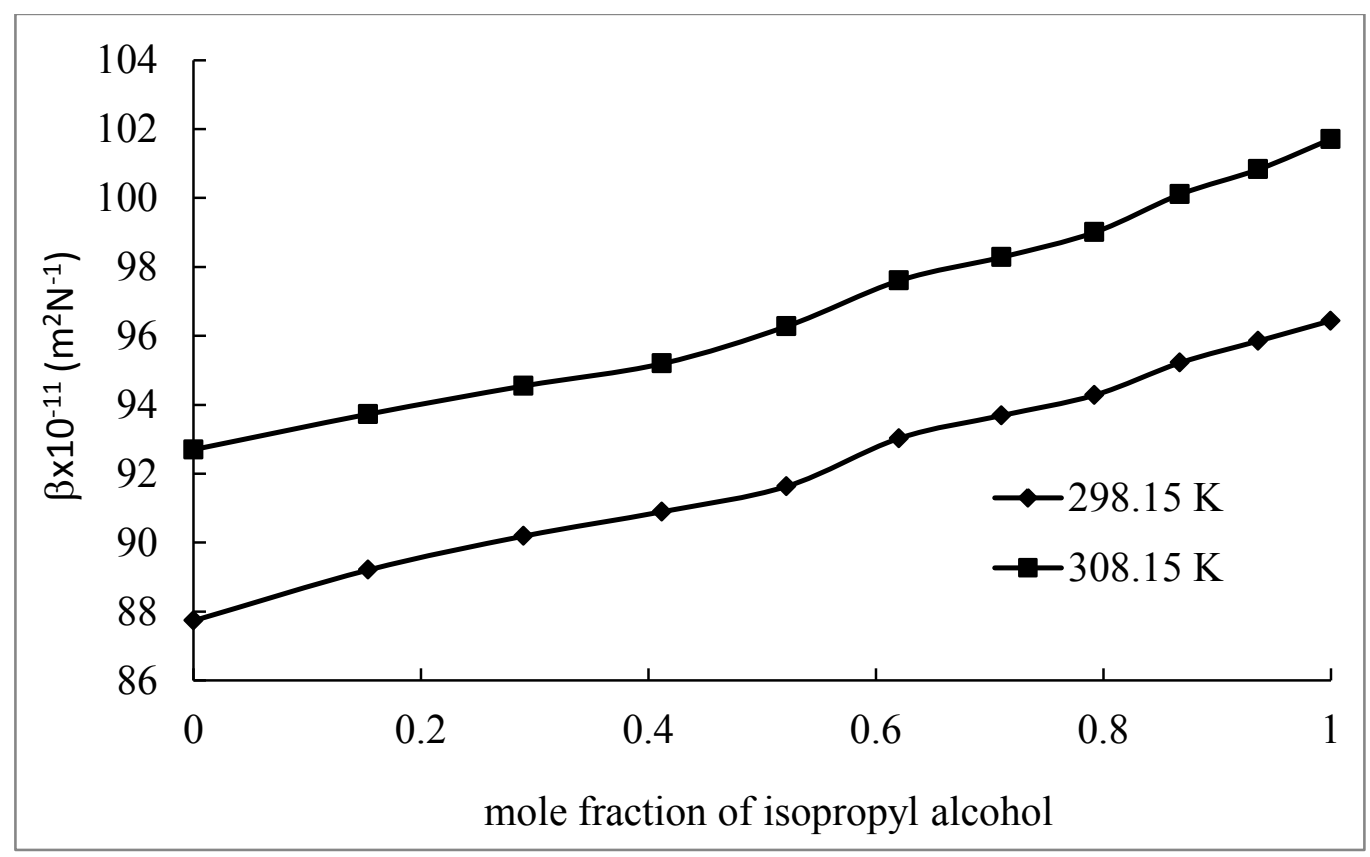

Fig. 1(b). Variation of adiabatic compressibility with mole fraction of isopropyl alcohol for isopropyl alcohol + MIBK mixture at different temperatures. 


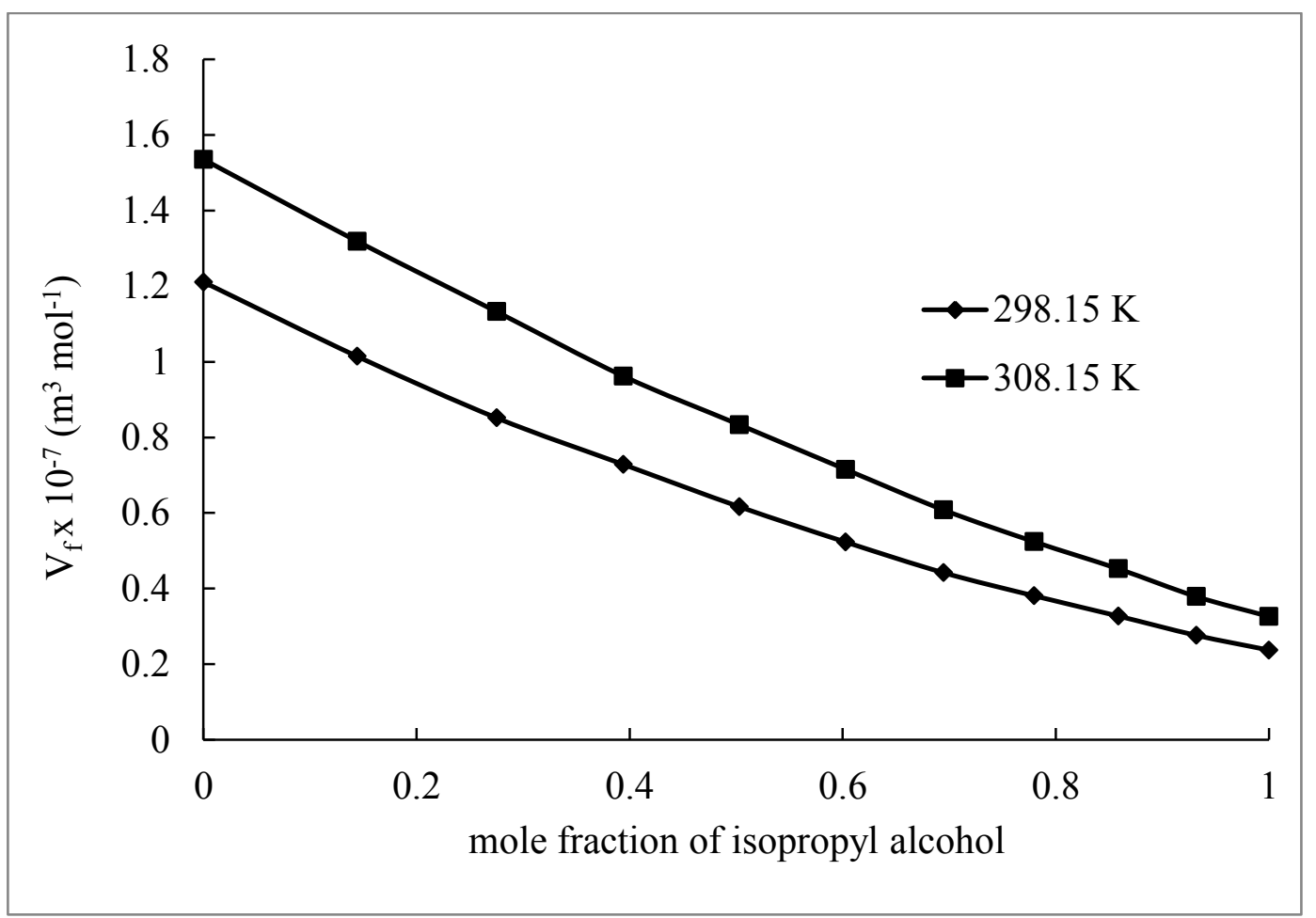

Fig. 2(a). Variation of free volume with mole fraction of isopropyl alcohol for isopropyl alcohol + acetophenone mixture at different temperatures.

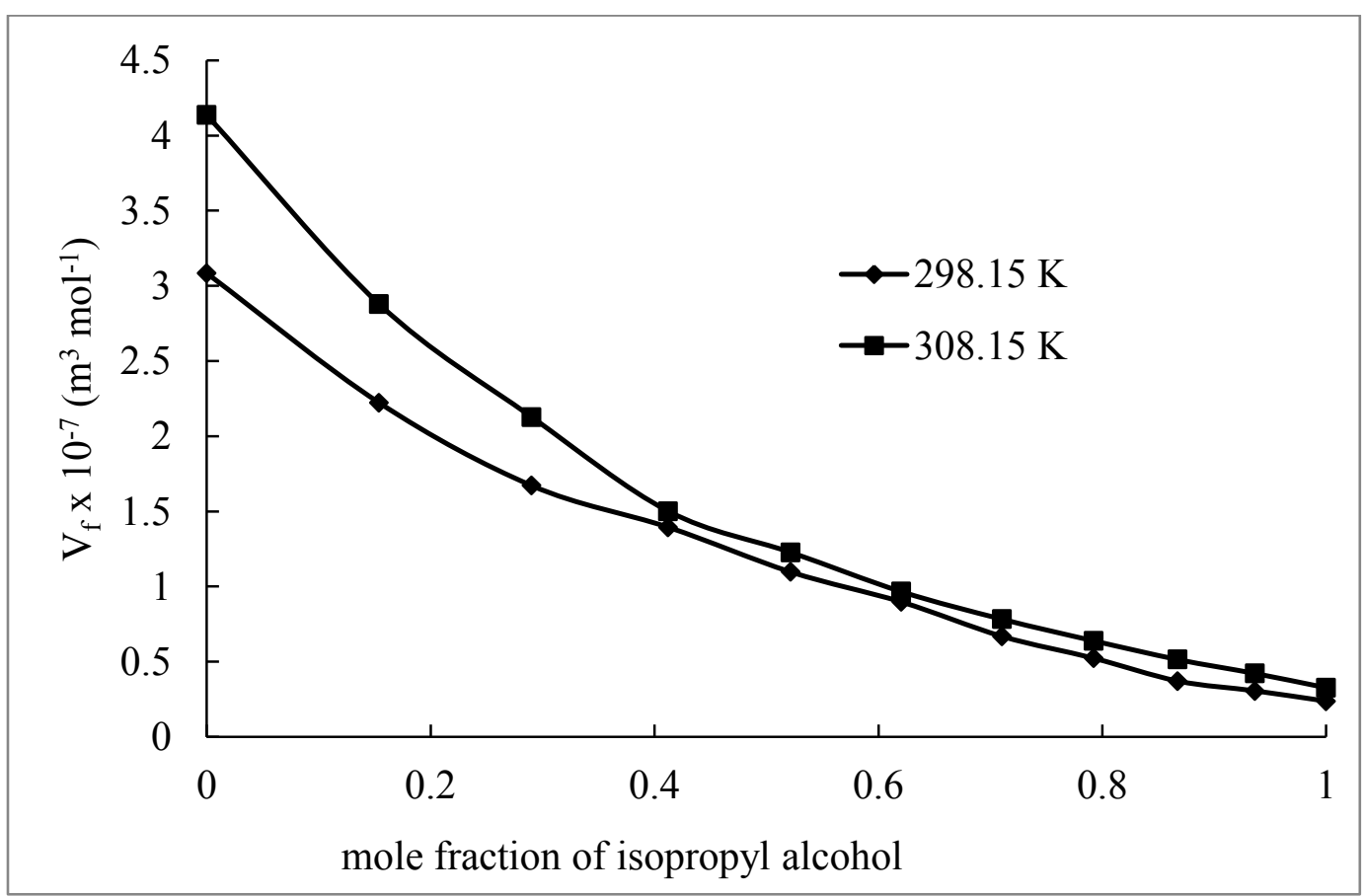

Fig. 2(b). Variation of free volume with mole fraction of isopropyl alcohol for isopropyl alcohol + MIBK mixture at different temperatures. 


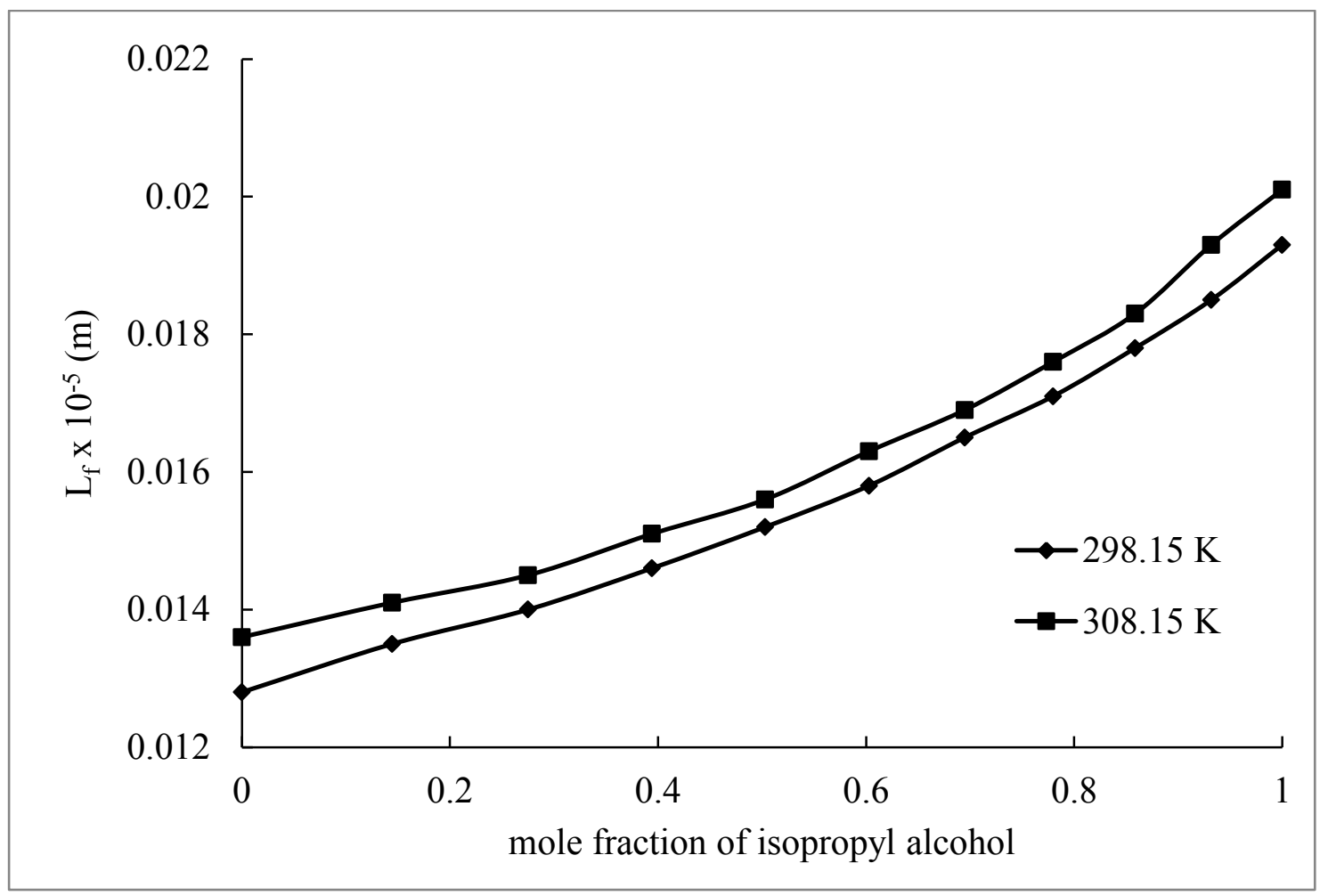

Fig. 3(a). Variation of free length with mole fraction of isopropyl alcohol for isopropyl alcohol + acetophenone mixture at different temperatures.

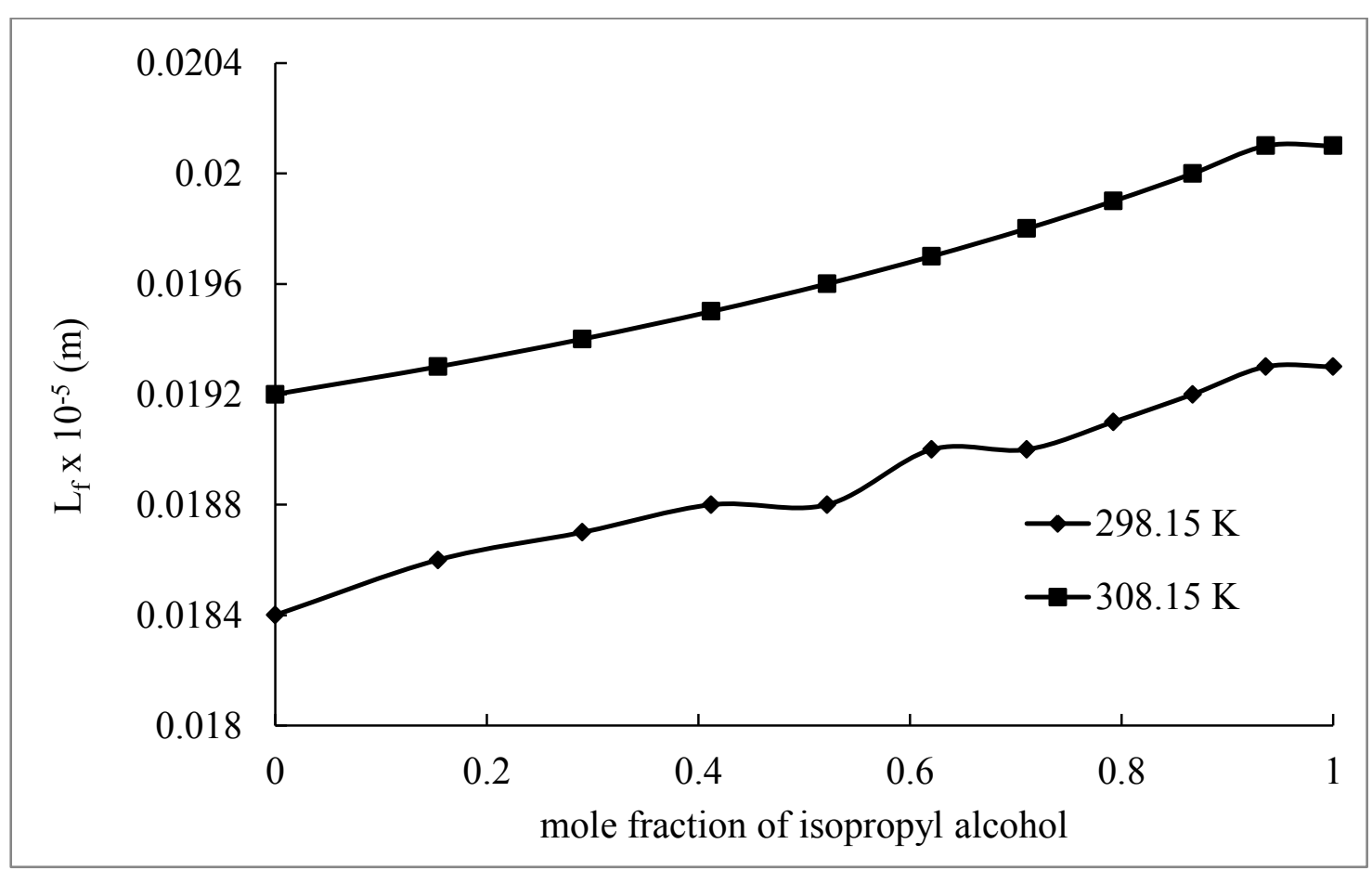

Fig. 3(b). Variation of free length with mole fraction of isopropyl alcohol for isopropyl alcohol + MIBK mixture at different temperatures. 
Adiabatic compressibility is a measure of intermolecular association or dissociation or repulsion. Singh and Kalsh [10] showed that the adiabatic compressibility should be independent of temperature and pressure for unassociated and weakly associated molecules. It also determines the orientation of the solvent molecules around the liquid molecules. The structural arrangement of the molecule affects the adiabatic compressibility.

Free volume is defined as the average volume in which the centre of the molecules can move inside the hypothetical cell due to the repulsion of surrounding molecules. Free volume can be calculated by different methods. Chellaiah et al [11], Erying et al [12], Mc Leod [13] and Hildebrand [14] have made a few approaches in calculating the free volume. Suryanarayana and Kuppusamy [15] on the basis of dimensional analysis, obtained an expression for free volume in terms of experimentally measurable parameters like ultrasonic velocity and viscosity and is given by eq (3). The free volume plays an important role in ultrasonic wave propagation in liquids. It also depends on temperature and pressure.

The free length is the distance between the surfaces of the neighbouring molecules. Generally, when the ultrasonic velocity increases, the value of the free length decreases. The decrease in intermolecular free length indicates the interaction between the solute and solvent molecules due to which the structural arrangement in the neighbourhood of constituent ions or molecules gets affected considerably.

From Figure 1(a) and 1(b) it is observed that as the molefraction of isopropyl alcohol increases the adiabatic compressibility values increases in the two systems and the values also increases with increase of temperature. Similar observations are made by Ali and Nain [16] in their binary mixtures and reported that the interactions become weaker with increase of temperature.

From Figure 2(a) and 2(b) it is observed that as the molefraction of isopropyl alcohol increases the free volume values decreases in the two systems and the values increase with increase of temperature.

From Figure 3(a) and 3(b) it is observed that as the molefraction of isopropyl alcohol increases the free length values increases in the two systems and also the values increase with increase of temperature.

The increase in $\beta$ and $\mathrm{L}_{\mathrm{f}}$ with mole fraction of isopropyl alcohol in all the mixtures indicate significant interaction between the components of the molecules of the mixture. The decrease in $\mathrm{u}$ and corresponding increase in $\mathrm{L}_{\mathrm{f}}$ with mole fraction is in accordance with the view proposed by Eyring and Kincard [17] and supports the existence of certain interactions.

\section{CONCLUSION}

Experimental data of the density, viscosity and ultrasonic velocity have been measured at $298.15 \mathrm{~K}$ and $308.15 \mathrm{~K}$. These data have been used to compute the parameters like adiabatic compressibility, free volume and free length. It clearly suggests the presence of interactions between the molecules of all the binary mixtures.

\section{References}

[1] Oswel S. L., Oswel P., Phalak R. P., J. Sol. Chem. 27 (1998) 507.

[2] Rajasekhar J., Naidu P., J. Chem. Eng. Data 41(1996) 373. 
[3] Kalidoss M., Srnivasamoorthy R., J. Pure Appl. Ultrason. 19 (1997) 9.

[4] Boch W., Miecznik P., Acoustics Lett. 10 (1986) 74.

[5] Subramanyam Naidu P., Ravindra Prasad K., J. Pure Applied Ultrason. 27 (2005) 15.

[6] Narendra K., Srinivasu Ch., Fakruddin Sk., Narayanamurthy P., J. Chem. Thermodyn. 43 (2011) 1604.

[7] Arnett E. M., Michel E. J., Murthy T. S. S. R., J. American Chem. Soc. 96 (1974) 3875.

[8] Perrin D. D., Armarego W. L. F., Purification of Lab. Chem., $3^{\text {rd }}$ ed., Pergamon Press, Oxford, 1980.

[9] Kannappan A. N., Palani R., Indian J. Phys. 70B (1996) 59.

[10] Singh D. P., Kalsh S. C., Acoustics Letters 14(10) (1991) 206.

[11] Chellaiah N., Sebesan R., Indian J. Pure Appl. Phys. 32 (1994) 315.

[12] Erying H., Hischfelder, J. Phys. Chem. 41 (1937) 249.

[13] McLeod D. B., Trans Farad Soc. 41 (1945) 771.

[14] Hildebrand J. H., J. Am. Chem. So.c 71 (1949) 2703.

[15] Suryanarayana C. V., Kuppusamy J., J. Acoust. Soc. Ind. 4 (1976) 75.

[16] Ali A., Nain A. K., Acoustic Letters 21 (1997) 77.

[17] Eyring H., Kincaid J. F., J. Chem. Phys. 6 (1938) 620.

[18] N. Santhi, P. L. Sabarathinam, J. Madhumitha, G. Alamelumangai, M. Emayavaramban, International Letters of Chemistry, Physics and Astronomy 2 (2013) 18-35.

[19] M. Durga Bhavani, A. Ratnakar, Ch. Kavith, International Letters of Chemistry, Physics and Astronomy 5 (2013) 1-6

[20] Y. Sreedevi, Ch. Srinivasu, Sk. Fakruddin, K. Narendra, B. R. Venkateswara Rao, Y. Nirmal Rajeev, International Letters of Chemistry, Physics and Astronomy 7(2) (2013) 120-124 